\title{
Pleural effusion post coronary artery bypass surgery: associations and complications
}

\author{
John D. L. Brookes ${ }^{1} \wedge$, Michael Williams ${ }^{1,2} \wedge$, Manish Mathew ${ }^{1},{\text { Tristan } \text { Yan }^{1,2,3,4,5} \text {, Paul Bannon }}^{1,2,5,6}$ \\ ${ }^{1}$ Department of Cardiothoracic Surgery, Royal Prince Alfred Hospital, New South Wales, Australia; ${ }^{2}$ Sydney Medical School, The University \\ of Sydney, New South Wales, Australia; ${ }^{3}$ Professor of Cardiovascular and Thoracic Surgery, Macquarie University, New South Wales, Australia; \\ ${ }^{4}$ Clinical Professor of Surgery, Faculty of Medicine, The University of Sydney, New South Wales, Australia; ${ }^{5}$ The Baird Institute, Newtown, New \\ South Wales, Australia; ${ }^{6}$ Bosch Professor of Surgery, Faculty of Medicine, The University of Sydney, New South Wales, Australia \\ Contributions: (I) Conception and design: All authors; (II) Administrative support: None; (III) Provision of study materials or patients: None; (IV) \\ Collection and assembly of data: JDL Brookes, M Williams; (V) Data analysis and interpretation: JDL Brookes, M Williams; (VI) Manuscript \\ writing: All authors; (VII) Final approval of manuscript: All authors. \\ Correspondence to: Dr. John D. L. Brookes. Department of Cardiothoracic Surgery, Royal Prince Alfred Hospital, Camperdown 2050, New South \\ Wales, Australia. Email: jdlbrookes@gmail.com.
}

Background: One of the most frequent complications of coronary artery bypass grafting (CABG) is pleural effusion. Limited previous studies have found post-CABG pleural effusion to be associated with increased length-of-stay and greater morbidity post-CABG. Despite this the associations of this common complication are poorly described. This study sought to identify modifiable risk factors for effusion post-CABG.

Methods: A retrospective cohort study of prospectively collected data assessed patients who underwent CABG over two-years. Data was collected for risk factors and sequelae related to pleural effusion requiring drainage.

Results: A total of 409 patients were included. Average age was $64.9 \pm 10.2$ years, $330(80.7 \%)$ were male. $59(14.4 \%)$ patients underwent drainage of pleural effusion post-CABG. Effusions were drained on average $9.9 \pm 8.4$ days post-CABG. Earlier removal of drain tubes and removal near time of extubation were associated with development of pleural effusion. Post-CABG pleural effusion was associated with post-operative renal impairment $(\mathrm{P}<0.01)$ and pericardial effusion $(\mathrm{P}<0.01)$. Patients with pleural effusion were more likely to require readmission to ICU $(\mathrm{P}<0.01)$, reintubation $(\mathrm{P}=0.03)$ and readmission to hospital $(\mathrm{P}=0.03)$.

Conclusions: Pleural effusion is a common complication of cardiac surgery and is associated with significant morbidity and resource utilization. This study identifies several associated complications that should be considered in the presence of pleural effusion. Modifiable associated factors in the management of drains that may contribute to accumulation of pleural effusion include: early removal of chest drains, higher outputs and removal during or close to mechanical ventilation. Further research is required to assess how adjusting these modifiable factors can decrease rates of effusion post-operatively.

Keywords: Coronary artery bypass graft (CABG); pleural effusion; pericardial effusion; intercostal catheter; intensive care

Submitted May 31, 2020. Accepted for publication Dec 17, 2020.

doi: $10.21037 /$ jtd-20-2082

View this article at: http://dx.doi.org/10.21037/jtd-20-2082

^ ORCID: John D. L. Brookes, 0000-0002-8568-6130; Michael Williams, 0000-0002-7002-9728; Tristan Yan, 0000-0002-7473-1522. 


\section{Introduction}

One of the most frequent complications of coronary artery bypass grafting (CABG) is pleural effusion. Pleural effusions may delay recovery, require further intervention such as drainage and predispose to other post-operative complications (1). In the modern era, with increasing patient comorbidity and the complexity of operations rates of effusion are increasing (2). Despite this there is no consensus on volume of drainage or timing that should guide drain removal $(3,4)$.

Limited previous studies have found post-CABG pleural effusion to be associated with longer length of stay and greater morbidity post-CABG $(1,5)$. Despite this the associated factors for this common complication is poorly described in the medical literature and few studies have examined potentially modifiable risk factors to decrease the rate of pleural effusion post-CABG.

The primary outcome of this study was to identify factors associated with developing pleural effusion post-CABG. Secondary outcomes were related effects on post-operative recovery including prolonged intubation, length of stay, other respiratory complications, readmission and mortality. We present the following article in accordance with the STROBE reporting checklist (available at http://dx.doi. org/10.21037/jtd-20-2082).

\section{Methods}

This retrospective cohort study of prospectively collected data assessed all patients who underwent CABG using a left internal mammary artery (LIMA) graft, but not bilateral mammaries across 2017-2018 at Royal Prince Alfred Hospital, Sydney, Australia. The Cardiothoracic Database (Redcap v8, Vanderbilt University) was reviewed to collate patients who underwent CABG. This yielded 409 patients for inclusion.

Data was collected for patient demographics: age, gender, renal function, dialysis status, diabetes, hypercholesterolaemia, smoking status, respiratory disease, body mass index, weight, peripheral vascular disease, preexisting arrhythmias, pre-operative myocardial infarction and type, pre-operative anticoagulation and antiplatelet exposure, left ventricular ejection fraction, previous cardiac surgery, INR, platelet levels, number of distal grafts, type of conduit used, urgency of procedure, cross clamp and bypass time, off-pump surgery, return to theatre, intensive care unit (ICU) length of stay, time to extubation, time to removal of mediastinal drains, amount of mediastinal drainage prior to removal at various time increments, transfusion requirements, post-operative renal failure, pericarditis, pericardial effusion requiring drainage, pleural effusion requiring drainage, post-operative weight gain, new post-operative arrhythmia, post-operative pneumonia, post-operative renal impairment, lowest postoperative haemoglobin, sternal wound infection, discharge destination, post-operative anticoagulation, mortality, postoperative myocardial infarction, post-operative arrest, reintubation, readmission to ICU, readmission to hospital within 30 days and hospital length of stay.

All patients had mediastinal or Pericardial and left pleural drains placed intra-operatively. These were routinely placed on underwater sealed drains $20 \mathrm{cmH}_{2} \mathrm{O}$ suction post-operatively. All patients were treated with diuretics post-operatively. Drainage of effusion was undertaken if considered clinically necessary at the discretion of the treating surgeon either via interventional radiology service or the cardiothoracic surgical team. These ranged from pigtail drains to $28 \mathrm{~F}$ surgical drains. They were also subsequently placed on underwater seal drains on $20 \mathrm{cmH}_{2} \mathrm{O}$ suction. There was no standard approach to removal of chest drains post-operatively within the unit during the study period. The study was conducted in accordance with the Declaration of Helsinki (as revised in 2013). The study was approved by the ethics board of Sydney Local Health District Royal Prince Alfred Hospital (Protocol No. X20$0208 \& 2020 /$ ETH01262), and individual consent for this retrospective analysis was waived.

\section{Statistical methods}

Data was analyzed using Microsoft Excel and Data Analysis Add on for Mac 2011, and Stata (Stata 15.1, Stata Corp, Texas USA).

Data for continuous variables is expressed as mean \pm standard deviation. Data for categorical variables is expressed as absolute numbers or relative proportions. Comparison of means between groups with normal distribution was determined via a Two-tailed $t$-test. Comparison of means between groups with non-normal distribution was via Mann-Whitney U test. Dichotomous variables were assessed by Chi squared test, or if small event size Fisher's exact test. $\mathrm{P}$ value 0.05 was considered to indicate a statistically significant result. 
Table 1 Baseline pre-operative factors associated with post-CABG pleural effusion

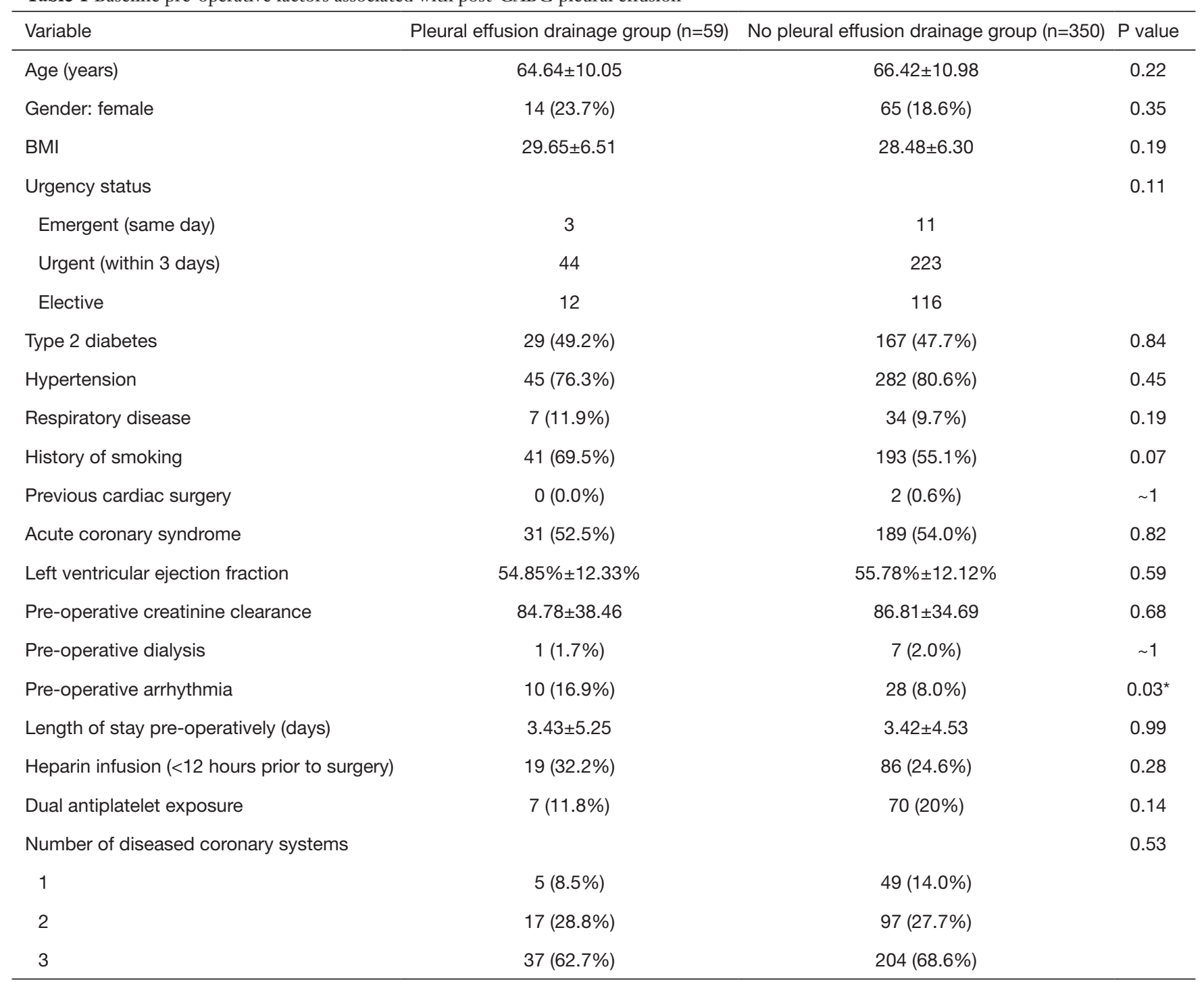

*, statistically significant $P$ value $<0.05$. CABG, coronary artery bypass grafting.

\section{Results}

Four hundred and nine [409] patients met inclusion criteria. Average age was $64.9 \pm 10.2$ years, $330(80.7 \%)$ were male. A total of 59 patients $(14.4 \%)$ underwent drainage of pleural effusion post-CABG. A total of 58 (98.3\%) had early effusions, within the first 30 days of surgery. Effusions were drained on average day $9.9 \pm 8.4$ days post-CABG. Baseline patient characteristics and operative factors relating to pleural effusion are outlined in Table 1. There was no statistically significant difference in pre-operative demographic details between those who did and did not undergo drainage of a post-operative effusion apart from patients requiring drainage were more likely to have a preexisting arrhythmia [10 (16.9\%) vs. 28 (8.0\%), $\mathrm{P}=0.03]$.

Intra-operative variables are outlined in Table 2. There was no difference in cross clamp $(70.61 \pm 33.62$ vs. $62.96 \pm 29.81$ mins, $\mathrm{P}=0.11)$ and bypass times $(91.08 \pm 36.41$ vs. $84.36 \pm 23.43$ mins, $\mathrm{P}=0.19$ ), or if the procedure was performed off pump [11 (18.6\%) vs. 85 (24.3\%), $\mathrm{P}=0.34]$.

Post-operative variables and associations are described in Table 3. Patients drained between $100-4,010 \mathrm{~mL}$ total prior to drain removal. Patients who required drainage of pleural effusion had a longer period of intubation $(29.44 \pm 87.49 \mathrm{vs}$. $11.52 \pm 14.55$ hours, $\mathrm{P}<0.01)$ and were more likely to have 
Table 2 Intra-operative factors associated with post-CABG pleural effusion

\begin{tabular}{|c|c|c|c|}
\hline Variable & Pleural effusion drainage group $(n=59)$ & No pleural effusion drainage group $(n=350)$ & $P$ value \\
\hline Off pump surgery & $11(18.6 \%)$ & $85(24.3 \%)$ & 0.34 \\
\hline Cross clamp time (mins) & $70.61 \pm 33.62$ & $62.96 \pm 29.81$ & 0.11 \\
\hline Bypass time (mins) & $91.08 \pm 36.41$ & $84.36 \pm 23.43$ & 0.19 \\
\hline
\end{tabular}

CABG, coronary artery bypass grafting.

Table 3 Post-operative factors associated with post-CABG pleural effusion

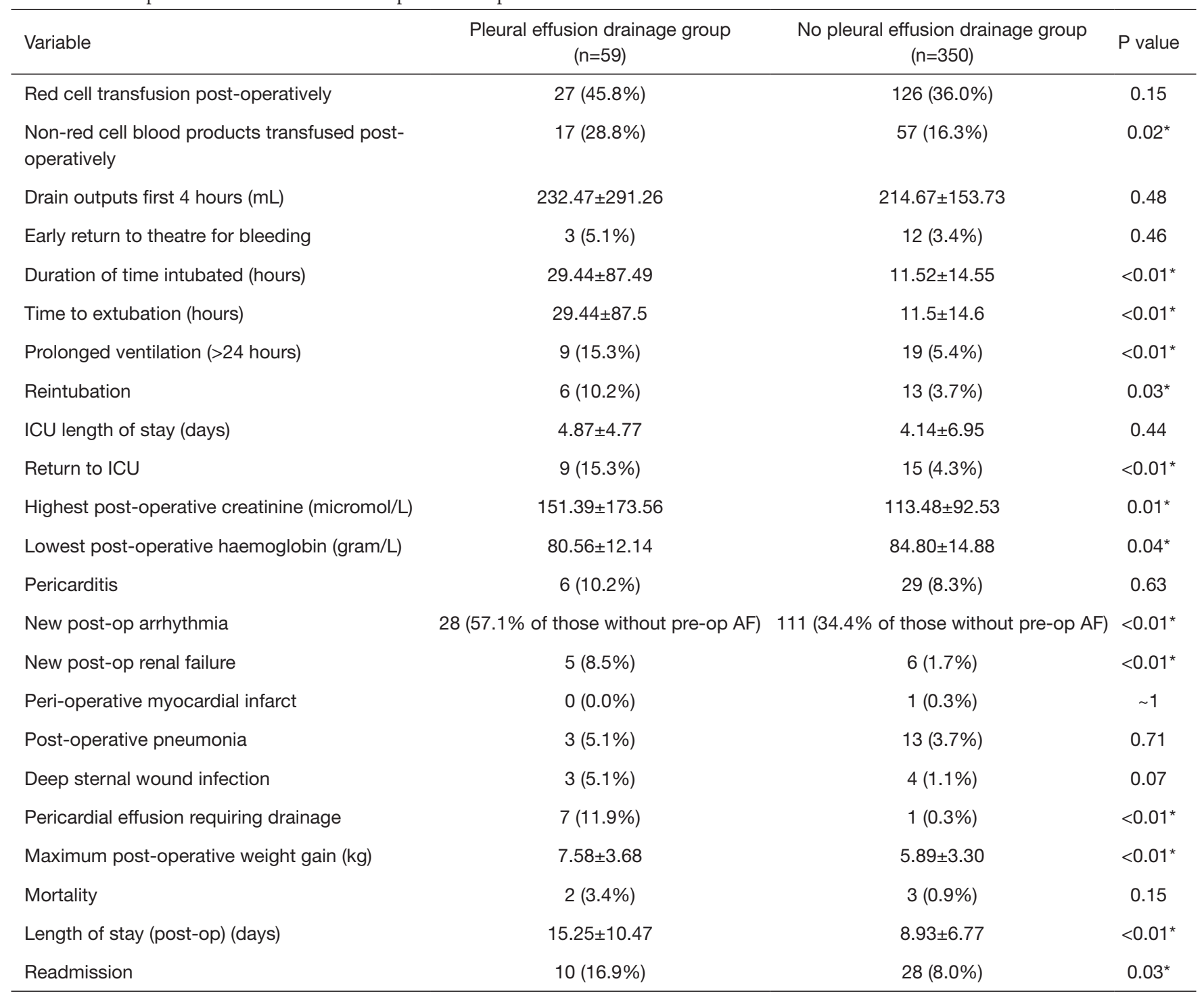

*, statistically significant $P$ value $<0.05$. CABG, coronary artery bypass grafting. 
Table 4 Drain management related factors associated with post-CABG pleural effusion

\begin{tabular}{|c|c|c|c|}
\hline Variable & $\begin{array}{l}\text { Pleural effusion drainage group } \\
\qquad(n=59)\end{array}$ & $\begin{array}{l}\text { No pleural effusion drainage group } \\
\qquad(\mathrm{n}=350)\end{array}$ & $P$ value \\
\hline Hours from operation to drain removed & $32.2 \pm 16.4$ & $37.2 \pm 22.5$ & $0.04^{*}$ \\
\hline Day of drain removal & & & 0.0495 \\
\hline Day 0 or 1 & $32(54.2 \%)$ & $142(40.6 \%)$ & \\
\hline Drain removed prior to extubation & $6(10.2 \%)$ & $10(2.9 \%)$ & $<0.01^{*}$ \\
\hline Drain removed within 4 hours post-extubation & $17(28.8 \%)$ & $15(4.3 \%)$ & $<0.01^{*}$ \\
\hline
\end{tabular}

*, statistically significant $P$ value $<0.05$. CABG, coronary artery bypass grafting.

had a prolonged post-operative intubation greater than 24 hours [9 (15.3\%) vs. 19 (5.4\%), $\mathrm{P}<0.01]$. Patients requiring drainage of a pleural effusion were more likely to develop a pericardial effusion requiring drainage [7 (11.9\%) vs. $1(0.3 \%), \mathrm{P}<0.01]$. There was an increased rate of nonred cell transfusion [17 (28.8\%) vs. 57 (16.3\%), $\mathrm{P}=0.02]$. Patients with pleural effusion also had increased postoperative weight gain $(7.58 \pm 3.68 v s .5 .89 \pm 3.30 \mathrm{~kg}, \mathrm{P}<0.01)$. Other significant post-operative variables were higher post-operative creatinine $(151.4 \pm 173.6$ vs. $113.48 \pm 92.5$, $\mathrm{P}=0.01)$ and new post-op renal failure $[5(8.5 \%)$ vs. $6(1.7 \%)$, $\mathrm{P}<0.01]$.

Factors related to drain removal are detailed in Table 4. Patients requiring drainage of a pleural effusion were more likely to have their chest drains removed earlier postoperatively $(32.2 \pm 16.4$ vs. $37.2 \pm 22.5$ hours, $\mathrm{P}=0.04)$, day one or earlier $v s$. day two or later $(\mathrm{P}=0.0495)$ and were more likely to have their drains removed whilst still intubated [6 $(10.17 \%)$ vs. $10(2.9 \%), \mathrm{P}<0.01]$ or soon after extubation [17 (28.8\%) vs. 15 (4.3\%), $\mathrm{P}<0.01]$. Removal of drains with $>140 \mathrm{~mL}$ drainage from midnight to 6 am ward round on day of removal was associated with increased rates of effusion $(\mathrm{P}=0.03)$.

Subsequently patients with pleural effusion were more likely to be readmitted from the ward to ICU $[9(15.3 \%) v s$. 15 (4.3\%), $\mathrm{P}<0.01$ ], were more likely to require reintubation [6 (10.2\%) vs. 13 (3.7\%), $\mathrm{P}=0.03$ ], and post-discharge were more likely to be readmitted to hospital [10 (16.9\%) vs. 28 (8.0\%), $\mathrm{P}=0.03$ ]. These patients also had longer postoperative duration of stay $(15.25 \pm 10.5$ vs. $8.93 \pm 6.8$ days, $\mathrm{P}<0.01)$.

\section{Discussion}

Pleural effusion after cardiac surgery remains a frequent complication, reported in $3.1 \%$ to $63 \%(1,6-8)$. This is dependent upon the size cut-offs and hard end points such as whether or not drainage was required. Prospective studies reporting small degrees of clinically insignificant effusion detected higher rates, whereas retrospective cohorts assessing hard end points such as drainage had lower rates. In the current study a rate of $14.4 \%$ of patients required drainage of their effusion post-operatively.

Pleural effusion is associated with numerous postoperative complications. Our study found pre-operative arrhythmias put patients at increased risk of post-operative effusion. Post-operative acute kidney injury (AKI) has previously been associated with peri-operative pulmonary complications (7). Additionally post-operative pleural effusion was associated with new atrial fibrillation consistent with previous findings by Labidi et al. (1). This may be related to poor oxygen saturation, overall fluid state and atrial stretch, or a serositic inflammatory picture not related to pericarditis. The current study did not capture the use or effect of medications to dampen inflammatory effect such as Colchicine previously shown in subsets of the COPPS, but not COPPS-2 studies to decrease rates of pleural effusion post-cardiac surgery $(9,10)$.

Pleural effusion was accompanied by pericardial effusion in $11.9 \%$ of cases, and $87.5 \%$ of significant pericardial effusion cases in this series requiring drainage occurred in patients with pleural effusion (likely due to a combination of inflammatory response to opening of the pleura, post- 
operative ooze from the LIMA bed, overflow from any pericardial collection into the open pleural space and postoperative fluid shift). The association between pericardial and pleural effusion has been previously well reported by Ashikhmina and Ikaheimo both in studies primarily investigating pericardial effusion $(2,11)$.

Pleural effusion accounts for significant resource utilization in addition to further intervention for drainage. Pleural effusion is associated with a significantly increased hospital length of stay-within this series by an average of 6.3 days. This is in keeping with the 8.7 days noted by Labidi et al. (1). Additionally it accounts for a significant burden of readmissions to ICU and to hospital. In this series patients were more than twice as likely to be readmitted to hospital if they had a significant pleural effusion. Within an analysis of readmissions across New York State post-CABG 4.1\% of readmissions were for symptomatic pleural effusions (12).

Ventilation time was significantly longer in patients who required drainage of pleural effusion (although only one patient required drainage of a pleural effusion prior to extubation). This reflects the findings of Colak et al. who noted a longer period of intubation in patients requiring drainage (5). This is also reflected in studies of patients in medical ICUs as periods of prolonged intubation are associated with development of pleural effusions (13) likely related to the altered respiratory mechanics and impeded diaphragmatic contraction $(14,15)$.

This cohort study is one of the first to identify modifiable drain management factors associated with the development of pleural effusion post-CABG. Patients who developed pleural effusion on average had their drains removed earlier, and those patients who had drains removed on post-operative day 1 were more likely to develop effusion requiring drainage compared to day 2 or later. Andreasen et al. conducted a randomized control trial to assess if early chest drain removal (midnight $v s$. morning of day one) effected rate of pericardial and pleural effusion requiring intervention (3). Their results that early chest drain removal was associated with increased rates of pleural and pericardial effusion, even if outputs were low support our findings. Additionally patients developing pleural effusion were also more likely to have had their drains removed whilst intubated or shortly after extubation. Whether this reflects altered chest wall mechanical factors in the ventilated patient, or failure of patients to move out of bed or roll when drains were removed earlier leading to a failure to expel pooled fluid is unclear. Additionally removal with drain outputs greater than $140 \mathrm{~mL}$ from midnight to the 6 am ward round was noted to have an increased rate of pleural effusion. Barring the small subset of patients who have issues with drain site pain, few patients will be significantly slowed in their post-operative progression by drains being left to post-operative day two, indeed those remaining intubated will not be slowed by this at all. We would therefore suggest leaving drains until patients are well clear of extubation and generally until day 2 allowing the patients ample time to sit up out of bed, move and drain pooled pleural fluid.

\section{Limitations}

This study is limited by its retrospective, observational nature and the lack of a control group. This is data from a single centre. The overall sample size is moderate and it is possible that certain factors associated with postoperative pleural effusion could have been overlooked due to lack of statistical power. The indication for drainage was at the discretion of the treating surgeon adding an element of heterogeneity within the cohort.

\section{Conclusions}

Pleural effusion is a common complication of cardiac surgery and it is associated with other postoperative morbidity and significant resource consumption. This study has identified a number of associated complications that may prompt screening for pleural effusion or should be considered in the presence of pleural effusion-including new renal failure, arrhythmia and pericardial effusion. Additionally we have identified several modifiable risk factors in terms of how drains are managed post-operatively that may contribute to accumulation of pleural effusion, such as early removal of chest drains, and removal of drains during or close to post-operative intubation. These outcomes suggest that to decrease rates of pleural effusion drains should be left in until day two postoperatively, not removed in patients who remain intubated or shortly after extubation (in the early post-operative period) and patients should have outputs $<140 \mathrm{~mL} / \mathrm{Hr}$ over 6 hours prior to removal. Further research is required to assess how adjusting practice to these modifiable factors can decrease rates of effusion post-operatively.

\section{Acknowledgments}

The authors extend their thanks to Lorna Beattie the Cardiothoracic Data Manager for Royal Prince Alfred Hospital for access to the Cardiothoracic Database and support.

Funding: None. 


\section{Footnote}

Reporting Checklist: The authors have completed the STROBE reporting checklist. Available at http://dx.doi. org/10.21037/jtd-20-2082

Data Sharing Statement: Available at http://dx.doi. org/10.21037/jtd-20-2082

Conflicts of Interest: All authors have completed the ICMJE uniform disclosure form (available at http://dx.doi. org/10.21037/jtd-20-2082). Prof. TDY serves as an unpaid Executive Editor-in-Chief (Cardiovascular Surgery) for Fournal Thoracic Disease from Feb 2014 to Jan 2022. The other authors have no conflicts of interest to declare.

Ethical Statement: The authors are accountable for all aspects of the work in ensuring that questions related to the accuracy or integrity of any part of the work are appropriately investigated and resolved. The study was conducted in accordance with the Declaration of Helskinki (as revised in 2013). The study was approved by the ethics board of Sydney Local Health District Royal Prince Alfred Hospital Protocol (No. X20-0208 \& 2020/ETH01262), and individual consent for this retrospective analysis was waived.

Open Access Statement: This is an Open Access article distributed in accordance with the Creative Commons Attribution-NonCommercial-NoDerivs 4.0 International License (CC BY-NC-ND 4.0), which permits the noncommercial replication and distribution of the article with the strict proviso that no changes or edits are made and the original work is properly cited (including links to both the formal publication through the relevant DOI and the license). See: https://creativecommons.org/licenses/by-nc-nd/4.0/.

\section{References}

1. Labidi M, Baillot R, Dionne B, et al. Pleural Effusions Following Cardiac Surgery. Chest 2009;136:1604-11.

2. Ashikhmina EA, Schaff HV, Sinak LJ, et al. Pericardial effusion after cardiac surgery: risk factors, patient profiles, and contemporary management. Ann Thorac Surg 2010;89:112-8.

3. Andreasen JJ, Sorensen GVB, Abrahamsen EF, et al. Early chest tube removal following cardiac surgery is associated with pleural and/ or pericardial effusions requiring invasive treatment. Eur J Cardiothorac Surg 2016;49:288-92.
4. Utter GH. The rate of pleural fluid drainage as criterion for the timing of chest drain removal: theoretical and practical considerations. Ann Thorac Surg 2013;96:2262-7.

5. Colak MC, Colak C, Erdil N, et al. Potential risk factors for early large pleural effusion after coronary artery bypass grafting surgery. Biomedical Res 2017;28:625-9.

6. Peng MC, Hou CJY, Li JY, et al. Prevalence of symptomatic large pleural effusions first diagnosed more than 30 days after coronary artery bypass graft surgery. Respirology 2007;12:122-6.

7. Ji Q, Mei YQ, Wang XS, et al. Risk factors for pulmonary complications following cardiac surgery with cardiopulmonary bypass. Int J Med Sci 2013;10:1578-83 .

8. Light RW, Rogers JT, Moyers JP, et al. Prevalence and clinical course of pleural effusions at 30 days after coronary artery and cardiac surgery. Am J Respir Crit Care Med 2002;166:1567-71.

9. Imazio $M$, Brucato A, Rovere ME, et al. Colchicine prevents early postoperative pericardial and pleural effusions. Am Heart J 2011;162:527-32.

10. Imazio $M$, Brucato A, Ferrazzi $P$, et al. Colchicine for prevention of postpericardiotomy syndrome and postoperative atrial fibrillation: The Copps-2 randomized clinical trial. J Am Med Assoc 2014;312:1016-23.

11. Ikaheimo MJ, Huikuri HV, Airaksinen KE, et al. Pericardial effusion after cardiac surgery incidence, relation to the type of surgery, antithrombotic therapy and early coronary bypass graft patency. Am Heart J 1988;116:97-102.

12. Hannan EL, Zhong Y, Lahey SJ, et al. 30-Day readmissions after coronary artery bypass graft surgery in New York State. J Am Coll Cardiol Cardiovasc Interv 2011;4:569-76.

13. Mattison LE, Sahn SA, Coppage L, et al. Pleural Effusions in the Medical ICU. Chest 1997;111:1018-23.

14. Barnas GM, Watson RJ, Green MD, et al. Lung and chest wall mechanical properties before and after cardiac surgery with cardiopulmonary bypass. J Appl Physiol 1994;76:166-75.

15. Gilbert TB, Barnas GM, Sequeira AJ. Impact of pleurotomy, continuous positive airway pressure, and fluid balance during cardiopulmonary bypass on lung mechanics and oxygenation. J Cardiothorac Vasc Anesth 1996;10:844-9.

Cite this article as: Brookes JDL, Williams M, Mathew M, Yan T, Bannon P. Pleural effusion post coronary artery bypass surgery: associations and complications. J Thorac Dis 2021;13(2):1083-1089. doi: 10.21037/jtd-20-2082 